\title{
ANALISIS PENERIMAAN PAJAK HIBURAN DI KOTA MANADO
}

\author{
Sikfrit Herold Marines Abast \\ Jantje Tinangon \\ Inggriani Elim
}

\author{
Fakultas Ekonomi dan Bisnis Jurusan Akuntansi \\ Universitas Sam Ratulangi Manado \\ email: sikfrit.abast@gmail.com
}

\begin{abstract}
ABSTRAK
Pajak Hiburan salah satu sumber Pendapatan Asli Daerah yang digunakan untuk membiayai penyelenggaraan roda pemerintahan dan pembangunan suatu daerah, dengan demikian daerah mampu melaksanakan otonomi daerah yang diamanatkan melalui Undang-undang. Metode penelitian yang digunakan dalam penelitian ini adalah metode analisis deskriptif kualitatif. Teknik penelitian yang digunakan adalah mengumpulkan data-data informasi, gambaran umum, permasalahan Pajak Hiburan pada Dinas Pendapatan Kota Manado yang digunakan untuk menganalisa dan mengolah data Pajak Hiburan tersebut. Hasil penelitian dapat disimpulkan kontribusi Pajak Hiburan terhadap Pendapat Asli Daerah Kota Manado sangat kurang, begitu pula terhadap pertumbuhan penerimaan Pajak Hiburan meskipun Pajak Hiburan terjadi peningkatan pertumbuhan penerimaanya namun berdasarkan indeks laju pertumbuhan penerimaan Pajak Hiburan dibawah rata-rata sehingga mendapat predikat tidak berhasil, dari sisi trend penerimaan Pajak Hiburan menggunakan metode kuadrat terkecil diperkirakan akan meningkat penerimaanya secara signifikan 10 tahun yang akan datang. Agar penerimaan dan pertumbuhan Pajak Hiburan Kota Manado memperoleh indeks predikat baik. Penulis menyarankan Dinas Pendapatan Kota Manado membangun sistim informasi perpajakan berbasis data base dan sistim pembayaran pajak online sehingga memudahkan fiskus mengawasi subjek Pajak Hiburan dalam melaksanakan kewajiban perpajakannya.
\end{abstract}

Kata kunci: analisis, pajak hiburan

\section{ABSTRACT}

Entertainment tax one source revenue sources used to finance the implementation of the wheels of government and the development of an area, so the area is able to implement regional autonomy mandated by the Act. The method used in this research is descriptive qualitative analysis method. The technique used in this study is to collect data information, the general picture, the problems on the Entertainment Tax Revenue Office of Manado City used to analyze and process data of the Entertainment Tax. The results of this study concluded contributions Entertainment Tax to the original local Opinions Manado is very less, so does the tax revenue growth despite Leisure Entertainment Tax increased the revenue growth but the growth rate of the index is based on entertainment tax revenue is below the average so that a predicate is not successful, in terms of Entertainment Tax receipts trend using the least squares method is expected to increase significantly the revenue coming 10 years. In order for acceptance and growth of Entertainment Tax Manado obtain good predicate index. The author suggests Manado City Revenue Service tax -based information systems to build a data base and online tax payment systems to facilitate tax authorities overseeing subject Entertainment Tax in implementing their tax obligations.

Keywords: analysis, entertainment tax 


\section{PENDAHULUAN}

\section{Latar Belakang}

Peranan Pajak Daerah sangat penting sebab pajak daerah merupakan salah satu sumber Pendapatan Asli Daerah yang digunakan untuk membiayai penyelenggaraan roda pemerintahan dan pembangunan demi meningkatkan kesejahteraan hidup masyarakat suatu daerah. Dengan demikian daerah tersebut mampu melaksanakan otonomi daerah yang diamanatkan melalui Undang-undang, yaitu mampu mengatur dan membiayai penyelenggaraan roda pemerintahan dan pembangunan secara mandiri.

Atas dasar itu Pemerintah Kota Manado menerbitkan Peraturan Daerah Nomor 2 Tahun 2011 tentang Pajak Daerah yang mengatur jenis-jenis pajak daerah apa yang akan dikenakan dikota manado, sebagai berikut:

1. Pajak Hotel;

2. Pajak Restoran;

3. Pajak Hiburan;

4. Pajak Reklame;

5. Pajak Penerangan Jalan;

6. Pajak Mineral Bukan Logam dan Batuan;

7. Pajak Parkir;

8. Pajak Air Tanah;

9. Pajak Sarang Burung Walet;

10. Pajak Bumi dan Bangunan sektor Perdesaan dan Perkotaan;

11. Bea Perolehan Hak Atas Tanah dan Bangunan.

Pajak Hiburan adalah salah satu jenis pajak daerah yang dikelola oleh Pemerintah Kota Manado tercermin dalam Target Penerimaan PAD Dinas Pendapatan Kota Manado Tahun Anggaran 2012 sebagai berikut.

Tabel 1. Target Penerimaan PAD Kota Manado Tahun Anggaran 2012

\begin{tabular}{llr}
\hline No. & \multicolumn{1}{c}{$\begin{array}{c}\text { Uraian } \\
\text { Jenis Pajak }\end{array}$} & $\begin{array}{c}\text { Target Penerimaan } \\
2012(\text { Rupiah) }\end{array}$ \\
\hline 1. & Pajak Hotel & 10.350 .000 .000 \\
2. & Pajak Restoran & 28.000 .000 .000 \\
3. & Pajak Hiburan & 4.250 .000 .000 \\
4. & Pajak Reklame & 4.200 .000 .000 \\
5. & Pajak Mineral Bukan Logam dan Batuan & 100.000 .000 \\
6. & Pajak Parkir & 2.100 .000 .000 \\
7. & Pajak Air Tanah & 500.000 .000 \\
8. & Pajak Sarang Burung Walet & 20.000 .000 \\
10. & BPHTB & 30.000 .000 .000 \\
11. & Retribusi Kebersihan & 6.300 .000 .000 \\
12. & Pajak Penerangan Jalan & 30.000 .000 .000 \\
\hline
\end{tabular}

Sumber Data Dinas Pendapatan Kota Manado

Dari jenis-jenis Pajak Daerah tersebut, penulis bermaksud menganalisa Penerimaan, Pertumbuhan dan Trend Pajak Hiburan dikota Manado, mengingat kota Manado salah satu kota di Indonesia yang menjadi tujuan wisata baik wisatawan domestik maupun internasional serta salah satu kota besar yang banyak menyediakan tempat hiburan sebagai fasilitas untuk para wisatawan

\section{Tujuan Penelitian}

Adapun tujuan dari penelitian ini adalah.

1. Untuk mengetahui kontribusi Pajak Hiburan terhadap Pendapatan Asli Daerah Kota Manado.

2. Untuk mengetahui pertumbuhan Pajak Hiburan di Kota Manado.

3. Untuk mengetahui perkembangan Pajak Hiburan di Kota Manado 


\title{
TINJAUAN PUSTAKA
}

\section{Konsep Akuntansi}

Halim (2004:138), Pengertian akuntansi dapat dijelaskan dengan dua pendekatan yaitu dari segi progresnya dan segi fungsinya.

1. Dilihat dari segi progresnya akuntansi adalah suatu keterampilan dalam mencatat, menggolongkan dan meringkas transaksi keuangan yang dilakukan suatu lembaga atau perusahaan, serta melaporkan hasilnya dalam suatu laporan keuangan.

2. Dilihat dari segi fungsinya akuntansi asalah suatu kegiatan jasa yang fungsinya menyediakan data kualitatif yang bersifat keuangan dari suatu lembaga atau suatu satuan usaha ekonomi yang dapat digunakan dalam pengambilan keputusan-keputusan ekonomi dalam rangka memilih berbagai alternative tindakan.

\author{
Akuntansi Pajak \\ 1. Kesatuan akuntansi \\ 2. Kesinambungan \\ 3. Harga pertukaran yang objektif \\ 4. Konsistensi dan konservatif
}

Muljono (2010:91), Pengertian akuntansi pajak adalah bidang akuntansi yang berkaitan dengan perhitungan perpajakan, yang mengacu pada peraturan, Undang-undang dan aturan pelaksanaanya. Prinsip-prinsip yang diakui dalam dalam akuntansi perpajakan meliputi :

\section{Konsep Pajak}

Soemitro dalam Mardiasmo (2011:1), pajak adalah iuran rakyat kepada kas negara berdasarkan undangundang (yang dapat dipaksakan) dengan tiada mendapat jasa timbal (kontraprestasi) yang langsung dapat ditunjukkan dan yang digunakan untuk membayar pengeluaran umum.

1. Mardiasmo (2011:1) ada dua fungsi pajak.

a. Fungsi budgetair, pajak sebagai sumber dana bagi pemerintah untuk membiayai pengeluaranpengeluarannya.

b. Fungsi mengatur (regulerend), pajak sebagai alat untuk mengatur atau melaksanakan kebijaksanaan pemerintah dalam bidang sosial dan ekonomi.

2. Mardiasmo (2011:5) pajak dapat dikelompokkan sebagai berikut.

a. Menurut golonganya, pajak langsung dan pajak tidak langsung.

b. Menurut sifatnya, pajak subjektif dan pajak objektif.

c. Menurut lembaga pemungutanya, pajak pusat dan pajak daerah.

3. Mardiasmo (2011:1) ada dua sistim pemungutan pajak.

a. Official assessment system.

b. Self assessment system.

c. With Holding System

\section{Pajak Daerah}

Pasal 1 Undang-undang Nomor 28 Tahun 2009 Tentang Pajak Daerah dan Retribusi Daerah, pajak daerah adalah iuran wajib yang dilakukan oleh orang pribadi atau badan kepada daerah tanpa imbalan langsung yang seimbang, yang dapat dipaksakan berdasarkan peraturan perundangan yang berlaku, yang digunakan untuk membiayai penyelenggaraan pemerintahan daerah dan pembangunan daerah, pajak daerah merupakan pendapatan daerah yang berasal dari pajak.

Pasal 2 ayat 1 dan 2 Undang-undang Nomor 28 Tahun 2009 Tentang Pajak Daerah dan Retribusi Daerah, pajak daerah terbagi dua yaitu pajak provinsi dan pajak daerah.

\section{Pajak Hiburan}

Pasal 1 angka 24 dan 25 Undang-Undang Nomor 28 Tahun 2009, Pajak Hiburan adalah pajak atas penyelenggaraan hiburan. Sedangkan yang dimaksud dengan hiburan adalah semua jenis tontonan, pertunjukan, permainan, dan atau keramaian yang dinikmati dengan dipungut bayaran. 


\section{Dasar Hukum Pemungutan Pajak Hiburan}

Dasar hukum pemungutan Pajak Hiburan pada kabupaten/kota adalah, Undang-undang Nomor 28 Tahun 2009 tentang Pajak Daerah dan Retribusi Daerah yang merupakan perubahan atas Undang-Undang No. 34 Tahun 2000 tentang Pajak Daerah dan Retribusi Daerah, Peraturan Pemerintah Nomor 65 Tahun 2001 tentang Pajak Daerah dan Retribusi Daerah. Peraturan Daerah Nomor 2 Tahun 2011 tentang Pajak Daerah.

\section{Subjek dan Objek Pajak Hiburan}

Pasal 43 Undang-undang Nomor 28 Tahun 2009 tentang pajak daerah dan retribusi daerah, menyebutkan subjek Pajak Hiburan yaitu sebagai berikut:

1. Subjek Pajak Hiburan adalah orang pribadi atau badan yang menikmati hiburan.

2. Wajib Pajak Hiburan adalah orang pribadi atau badan yang menyelenggarakan hiburan.

\section{METODE PENELITIAN}

\section{Jenis Data dan Sumber Data}

\section{Jenis Data}

a. Data kualitatif, data kualitatif dalam penelitian ini adalah informasi yang diperoleh dari hasil wawancara kepada pimpinan dan pegawai yang bekerja pada objek penelitian yaitu Dinas Pendapatan Kota Manado.

b. Data kuantitatif, data kuantitatif dalam penelitian ini adalah daftar target dan realisasi penerimaan Pendapatan Asli Daerah tahun 2008-2012 yang diperoleh dari objek penelitian yaitu Dinas Pendapatan Kota Manado.

\section{Sumber Data}

a. Data Primer, data primer dalam penelitian ini adalah data yang diperoleh dengan survey lapangan yang menggunakan semua metode pengumpulan data original.

b. Data Sekunder, data sekunder dalam penelitian ini berupa data-data target dan realisasi penerimaan pajak hiburan yang berasal dari Dinas Pendapatan Kota Manado.

\section{Teknik Pengumpulan Data}

a. Studi Kepustakaan, yaitu mempelajari teori-teori serta mencatat dari buku-buku, literature, jurnal, serta bahan-bahan informasi lainnya yang berhubungan dengan Pajak Hiburan.

b. Studi Lapangan, yaitu mengumpulkan data-data yang terdapat pada Dinas Pendapatan Kota Manado

\section{Metode Analisis}

Penelitian ini menggunakan teknik analisis deskriptif kualitatif

\section{Analisis Kontribusi}

Untuk menghitung kontribusi penerimaan Pajak Hiburan terhadap Pendapatan Asli Daerah maka digunakan rumus sebagai berikut:

\section{Sumber Halim (2004)}

Kontribusi Pajak Hiburan Terhadap Pendapatan Asli Daerah kemudian dinilai berdasarkan kriteria yang telah disusun pada tabel 3.

\section{Tabel 3. Kriteria Kinerja Keuangan}

\begin{tabular}{cc}
\hline Presentase Kinerja & Kriteria \\
Keuangan & Sangat Kurang \\
$0-10.00 \%$ & Kurang Baik \\
$10.10-20.00 \%$ & Cukup \\
$20.10-30.00 \%$ & Sedang \\
$30.10-40.00 \%$ & Baik \\
$40.10-50.00 \%$ & Sangat Baik \\
Lebih Dari 50.00\% & \\
\hline Sumber Halim (2004) &
\end{tabular}




\section{Analisis Laju Pertumbuhan}

Laju pertumbuhan Pajak Hiburan menunjukkan kemampuan Dinas Pendapatan dalam mempertahankan dan meningkatkan keberhasilannya dalam memungut Pajak Hiburan, rumus untuk menghitung laju pertumbuhan adalah:

Sumber Halim (2004)

Skala pengukuran laju pertumbuhan Pajak Hiburan didasarkan pada kriteria yang disusun pada tabel 4.

Tabel 4. Kriteria Laju Pertumbuhan

\begin{tabular}{cc}
\hline $\begin{array}{c}\text { Presentase Laju } \\
\text { Pertumbuhan }\end{array}$ & Kriteria \\
\hline $85-100 \%$ & Sangat Berhasil \\
$70-84 \%$ & Berhasil \\
$55-69 \%$ & Cukup Berhasil \\
$30-54 \%$ & Kurang Berhasil \\
Kurang dari $30 \%$ & Tidak Berhasil \\
\hline
\end{tabular}

Sumber Halim (2004)

\section{Analisis Trend}

Analisis trend dalam Pajak Hiburan untuk mengetahui estimasi atau ramalan penerimaan Pajak Hiburan di tahun-tahun yang akan datang. Rumus untuk menghitung analisis trend time series dalam kuadrat terkecil:

$$
\mathbf{Y}=\mathbf{a}+\mathbf{b X}
$$

Keterangan :

$\mathrm{Y}=$ variabel yang dicari trendnya

$\mathrm{X}=$ variable waktu (tahun)

$\mathrm{a}=\Sigma \mathrm{Y} / \mathrm{N}$ dan

$\mathrm{b}=\Sigma \mathrm{XY} / \Sigma \mathrm{X} 2$

\section{Teknik Analisis Data}

Proses analisis data yang digunakan dalam penelitian ini adalah:

1. Mengumpulkan data-data dan informasi yang berhubungan dengan judul penelitian.

2. Memperoleh gambaran umum dari objek penelitian secara keseluruhan serta mengetahui permasalahan yang ada.

3. Menganalisa dan mengolah data perhitungan Pajak Hiburan yang diperoleh.

4. Membuat kesimpulan dan memberikan saran yang dianggap perlu sebagai perbaikan dalam masalah yang ada.

\section{HASIL PENELITIAN DAN PEMBAHASAN}

\section{Hasil Penelitian}

Tabel 5. Realisasi Pendapatan Asli Daerah Kota Manado Tahun 2008-2012

\begin{tabular}{cccc}
\hline No. & $\begin{array}{c}\text { Tahun } \\
\text { Anggaran }\end{array}$ & $\begin{array}{c}\text { Target Pendapatan Asli } \\
\text { Daerah (Rupiah) }\end{array}$ & $\begin{array}{c}\text { Realisasi Pendapatan Asli } \\
\text { Daerah (Rupiah) }\end{array}$ \\
\hline 1 & 2008 & 52.250 .000 .000 & 54.715 .561 .525 \\
2 & 2009 & 63.007 .373 .000 & 73.481 .423 .371 \\
3 & 2010 & 74.854 .540 .000 & 68.205 .163 .422 \\
4 & 2011 & $109.946 .708,000$ & 93.364 .135 .117 \\
5 & 2012 & 132.210 .650 .825 & 135.204 .783 .495 \\
\hline
\end{tabular}

Sumber Data Dinas Pendapatan Kota Manado 
Tabel 5. menunjukkan pada umumnya penerimaan PAD Kota Manado mengalami peningkatan dari tahun ketahun, kecuali tahun 2010 dan 2011 yang mengalami penurunan sebesar $-8,9 \%$ dan $-15,1 \%$. Selanjutnya PAD mengalami kenaikan kembali.

Tabel 6. Realisasi ajak Hiburan Kota Manado Tahun 2008-2012

\begin{tabular}{cccc}
\hline No. & $\begin{array}{c}\text { Tahun } \\
\text { Anggaran }\end{array}$ & $\begin{array}{c}\text { Target Pajak Hiburan } \\
\text { (Rupiah) }\end{array}$ & $\begin{array}{c}\text { Realisasi Pajak Hiburan } \\
\text { (Rupiah) }\end{array}$ \\
\hline 1 & 2008 & 1.400 .000 .000 & 1.653 .026 .831 \\
2 & 2009 & 1.650 .000 .000 & 1.950 .072 .379 \\
3 & 2010 & 2.005 .000 .000 & 2.180 .879 .823 \\
4 & 2011 & 2.526 .000 .000 & 2.897 .097 .211 \\
5 & 2012 & 4.250 .000 .000 & 3.389 .256 .027 \\
\hline
\end{tabular}

Sumber Data Dinas Pendapatan Kota Manado

Tabel 5. dan 6. data penerimaan daerah Kota Manado selama periode Tahun Anggaran 2008-2012 yang berhubungan dengan permasalahan yang sedang diteliti. Diantaranya yaitu Target Penerimaan Pajak Hiburan, data Realisasi Pajak Hiburan, dan data Realisasi Pendapatan Asli Daerah yang merupakan jumlah dari Pendapatan Asli Daerah.

\section{Pembahasan}

Kontribusi Pajak Hiburan Terhadap Pendapatan Asli Daerah Kota Manado Tahun 2008-2012

Kontribusi rata-rata tiap tahun sebesar 2,80\%, membuktikan bahwa Pajak Hiburan mampu memberikan kontribusi terhadap PAD Kota Manado. Dapat dilihat pada tabel dibawah ini.

Tabel 7. Kontribusi Pajak Hiburan Terhadap Pendapatan Asli Daerah Kota Manado

\begin{tabular}{cccc}
\hline $\begin{array}{c}\text { Tahun } \\
\text { Anggaran }\end{array}$ & $\begin{array}{c}\text { Realisasi Pajak } \\
\text { Hiburan (Rp) }\end{array}$ & $\begin{array}{c}\text { Realisasi Pendapatan } \\
\text { Asli Daerah (Rp) }\end{array}$ & $\begin{array}{c}\text { Kontribusi } \\
(\%)\end{array}$ \\
\hline 2008 & 1.653 .026 .831 & 54.715 .561 .525 & 3,02 \\
2009 & 1.950 .072 .379 & 73.481 .423 .371 & 2,65 \\
2010 & 2.180 .879 .823 & 68.205 .163 .422 & 3,20 \\
2011 & 2.897 .097 .211 & 93.364 .135 .117 & 3,10 \\
2012 & 3.389 .256 .027 & 135.204 .783 .495 & 2,51 \\
\hline
\end{tabular}

Sumber Data Olahan 2013

Namun dalam kriteria kinerja keuangan pajak hiburan mendapat skala peringkat sangat kurang. Dapat dilihat pada tabel dibawah ini.

Tabel 8. Kriteria Kinerja Keuangan Pajak Hiburan

\begin{tabular}{ccc}
\hline $\begin{array}{c}\text { Tahun } \\
\text { Anggaran }\end{array}$ & $\begin{array}{c}\text { Persentase Kinerja } \\
\text { Keuangan }\end{array}$ & Kriteria \\
\hline 2008 & 3,02 & Sangat Kurang \\
2009 & 2,65 & Sangat Kurang \\
2010 & 3,20 & Sangat Kurang \\
2011 & 3,10 & Sangat Kurang \\
2012 & 2,51 & Sangat Kurang \\
\hline
\end{tabular}

Sumber Data Olahan 2013 


\section{Pertumbuhan Pajak Hiburan Kota Manado Tahun 2008-2012}

Pertumbuhan Pajak Hiburan di Kota Manado mengalami proses naik-turun, dimana pada tahun 2009 mendapat persentase $17,97 \%$ dan pada tahun 2010 mengalami penurunan dengan persentase $11,84 \%$, pada tahun 2011 mengalami kenaikan sebesar 32,84\% dan untuk tahun 2012 mengalami penurunan kembali sebesar 17,01\%. Dapat dilihat pada dibawah ini.

\section{Tabel 9. Pertumbuhan Pajak Hiburan Kota Manado}

\begin{tabular}{ccc}
\hline $\begin{array}{c}\text { Tahun } \\
\text { Anggaran }\end{array}$ & $\begin{array}{c}\text { Realisasi } \\
\text { (Rupiah) }\end{array}$ & $\begin{array}{c}\text { Pertumbuhan } \\
(\%)\end{array}$ \\
\hline 2008 & 1.653 .026 .831 & - \\
2009 & 1.950 .072 .379 & 17,97 \\
2010 & 2.180 .879 .823 & 11,84 \\
2011 & 2.897 .097 .211 & 32,84 \\
2012 & 3.389 .256 .027 & 17,01 \\
\hline
\end{tabular}

\section{Sumber Data Olahan 2013}

Dengan melihat skala laju pertumbuhan Pajak Hiburan, dapat disimpulkan laju pertumbuhan pajak hiburan tidak berhasil, hal ini tercermin pada tabel dibawah ini.

Tabel 10. Laju Pertumbuhan Pajak Hiburan Kota Manado

\begin{tabular}{ccc}
\hline $\begin{array}{c}\text { Tahun } \\
\text { Anggaran }\end{array}$ & $\begin{array}{c}\text { Persentase Kinerja } \\
\text { Keuangan }\end{array}$ & Kriteria \\
\hline 2008 & - & - \\
2009 & 17,97 & Tidak Berhasil \\
2010 & 11,84 & Tidak Berhasil \\
2011 & 32,84 & Kurang Berhasil \\
2012 & 17,01 & Tidak Berhasil \\
\hline
\end{tabular}

Sumber Data Olahan 2013

\section{Analisis Trend Kontribusi Pajak Hiburan Kota Manado}

Analsis trend dalam penerimaan kontribusi Pajak Hiburan di Kota Manado digunakan untuk melihat dan menghitung seberapa besar penerimaan kontribusi pajak hiburan dalam kurun waktu sepuluh tahun kedepan. Perhitungan estimasinya dapat kita lihat pada tabel dibawah ini.

Tabel 11. Analisis Trend Kontribusi Pajak Hiburan Terhadap Pendapatan Asli Daerah Kota Manado

\begin{tabular}{ccccc}
\hline Tahun & Kontribusi $(\mathrm{Y})$ & $\mathrm{X}$ & $\mathrm{XY}$ & $\mathrm{X}^{2}$ \\
\hline 2008 & 3,02 & -2 & $-6,04$ & 4 \\
2009 & 2,65 & -1 & $-2,65$ & 1 \\
2010 & 3,20 & 0 & 0 & 0 \\
2011 & 3,10 & 1 & 3,10 & 1 \\
2012 & 2,51 & 2 & 5,02 & 4 \\
Jumlah & 14,48 & & $-0,57$ & 10 \\
\hline
\end{tabular}

Sumber Data Olahan 2013 


$$
\begin{array}{ll}
a=\frac{14,8}{5} & b=\frac{-0,57}{10} \\
a=2,89 & b=-0,057
\end{array}
$$

Persamaan garis liniernya adalah $\mathrm{Y}=2,89+(-0,057) \mathrm{X}$. Dengan menggunakan persamaan tersebut, dapat diramalkan penerimaan Pajak Hiburan untuk tahun 2020 adalah : $\mathrm{Y}=2,89+(-0,057) 8$ (untuk tahun 2020 nilai X adalah 8), sehingga : $\mathrm{Y}=2,89+(-0,456)=2,434$, artinya penerimaan Pajak Hiburan terhadap Pendapatan asli Daerah Kota Manado pada tahun 2020 diperkirakan sebesar 243,4\%.

\section{PENUTUP}

\section{Kesimpulan}

1. Kontribusi penerimaan pajak hiburan terhadap pendapatan asli daerah Kota Manado dari tahun $2008-2012$ tidak stabil, pada tahun 2008 pajak hiburan memberikan kontribusi sebesar 3,02\%. Pada tahun 2009, kontribusi pajak hiburan menurun menjadi sebesar 2,65\%. Selanjutnya pada tahun 2010 kontribusi pajak hiburan meningkat jauh, yaitu sebesar 3,20\%. Dan pada tahun 2011 kontribusi pajak hiburan kembali menurun sehingga menjadi 3,10\%. Namun pada tahun 2012 kontribusi pajak hiburan menurun drastis menjadi $2,51 \%$. Maka pada tahun 2008 - 2012 pajak hiburan memberikan kontribusi rata-rata sebesar 2,80\%.

2. Laju pertumbuhan Pajak Hiburan di Kota Manado mengalami proses naik-turun, dimana pada tahun 2009 mendapat persentase $17,97 \%$ dan pada tahun 2010 mengalami penurunan dengan persentase 11,84\%, pada tahun 2011 mengalami kenaikan sebesar 32,84\% dan untuk tahun 2012 mengalami penurunan kembali sebesar $17,01 \%$.

3. Dalam analisis trend dengan menggunakan metode kuadrat terkecil diperkirakan penerimaan Pajak Hiburan pada tahun 2020 terhadap Pendapatan Asli Daerah Kota Manado sebesar 243,4\%.

\section{Saran}

Untuk meningkatkan penerimaan pajak hiburan, Dinas Pendapatan Kota Manado perlu membangun sistim informasi perpajakan berbasis data base dan pembayaran pajak hiburan online sehingga memudahkan fiskus mengawasi para subjek Pajak Hiburan dalam melaksanakan kewajiban perpajakannya. 


\section{DAFTAR PUSTAKA}

Halim, Abdul, 2004, Akuntansi Keuangan Daerah, Penerbit PT Salemba Empat, Jakarta.

Muljono, Djoko, 2010 Panduan Brevet Pajak : Akuntansi pajak dan Ketentuan Umum Perpajakan, Penerbit Andi Jogjakarta.

Mardiasmo, 2000, Pajak Daerah dan Retribusi Daerah, Penerbit Andi, Yogyakarta.

Mardiasmo, 2011, Perpajakan Edisi Revisi 2011, Penerbit Andi, Yogyakarta.

Siahaan, Marihot, 2005, Pajak Daerah dan Retribusi Daerah, Penerbit PT. Raja Grafindo Persada, Jakarta.

Waluyo, 2011, Perpajakan Indonesia Edisi 10 Buku 1, Penerbit Salemba Empat, Jakarta.

-Undang-undang RI No. 33 Tahun 2004 Tentang Perimbangan Keuangan Antara Pemerintah Pusat Dengan Pemeritah Daerah.

--Undang-undang RI No. 28 Tahun 2007 tentang Ketentuan Umum dan Tata Cara Perpajakan.

-Undang-undang Replublik Indonesia Nomor 28 Tahun 2009 Tentang Pajak Daerah dan Retribusi Daerah.

-Peraturan Daerah Kota Manado Nomor 2 Tahun 2011 tentang Pajak Daerah.

http://ssantoso.blogspot.com/2008/08/analisis-trend-materi-x-pengertian-dan.html, Diakses Agustus, 03 , 2013.

http://id.wikipedia.org/wiki/Analisis_tren, Diakses Agustus, 03 , 2013.

http://id.scribd.com/doc/48417459/ANALISIS-TREND, Diakses Agustus, 03 , 2013. 